\section{A rare cause of mechanical bowel obstruction in a young adult}
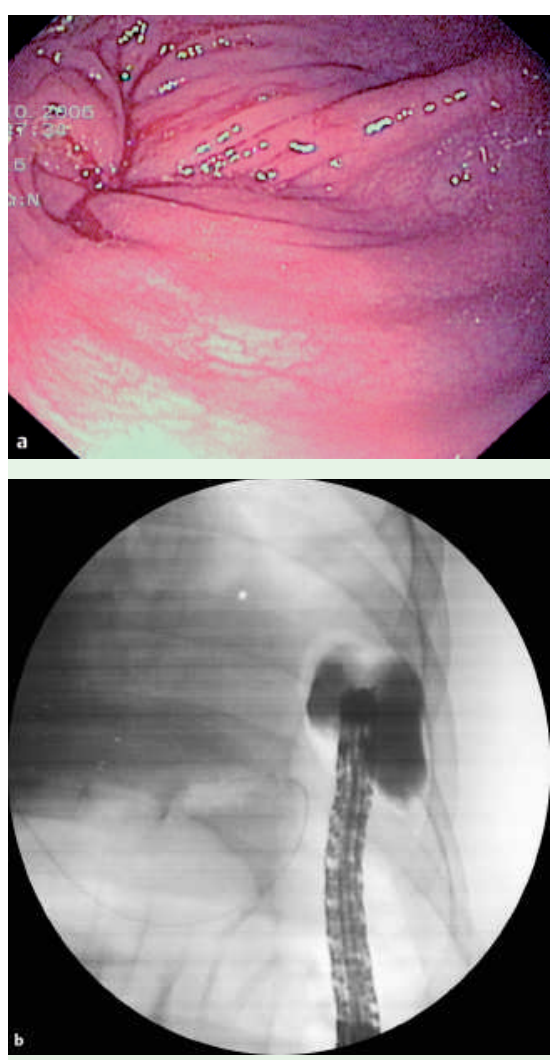

Fig. 1 a Mucosa in the left flexure. b Radiographic examination during colonoscopy; left flexure filled with contrast agent, lateral to the heart. Gastric tube in situ.

An 18-year-old male patient was referred for decompression colonoscopy having been admitted 2 days previously for bowel obstruction.

Upon admission, the patient had slight abdominal distension. Analgesic and laxative treatments were initiated but proved ineffective, and conventional radiography showed increasing distension of the cecum. Colonoscopy was performed up to the left colonic flexure ( Fig. $1 \mathbf{a}$ ), and radiographic contrast agent did not reach the transversum ( Fig. 1b). Abdominal computed tomography confirmed a mechanical ileus with herniation of the left colon flexure. Laparotomy was performed, and a $3 \mathrm{~cm}$ wide hiatus was found in the dorsolateral part of the diaphragm. The hernia was reposed, the diaphragm sutured, and part of the great omentum resected because of ischemia. The patient recovered without

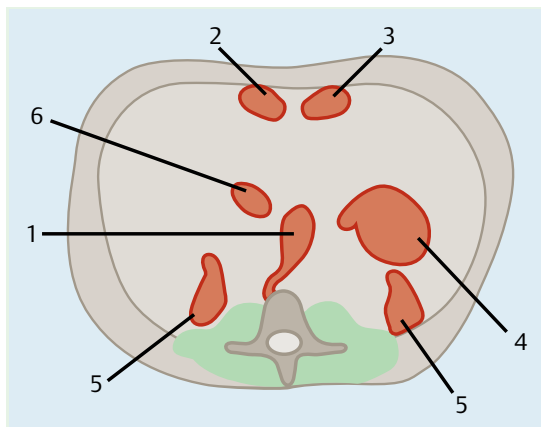

Fig. 2 Localization of hiatal hernias (with kind permission of R.W. Günther, MD, Department of Diagnostic Radiology, University of Aachen, Germany). 1. Hiatal hernia; 2. Morgagni's hernia right; 3. Larrey's hernia left; 4. Traumatic hernia; 5. Bochdaleck's hernia; 6. Caval hiatus in the diaphragm.

complications and was discharged 7 days postoperatively.

The prevalence of congenital diaphragmatic hernias is reported to be $4.8 / 10000$ births [ $1-3]$. If symptoms of congenital diaphragmatic herniation manifest later, in children or adults, gastrointestinal problems such as nausea, vomiting, abdominal pain, or bowel obstruction are most common [3]. In some reports of late-presenting hernias, bowel stricture was misdiagnosed as pneumothorax, basal pneumonia, or empyema [4,5]. Diagnosis is most often established with computed tomography.

The most common congenital hernia (prevalence $6 \%$ ), occurs in the posterolateral parts of the left diaphragm, and is known as Bochdalek's hernia [5]. Retrosternal hernia occurring on the right side, known as Morgagni's hernia, or retrosternal left-sided hernia, known as Larrey's hernia, is less common ( $\bullet$ Fig. 2 ). We believe that the most likely cause of our patient's problem was a rare, late manifestation of a congenital diaphragmatic hernia of none of the above-described types. Regardless of classification, symptomatic diaphragmatic hernia is a rare cause of mechanical bowel obstruction in young adults. If colonoscopy is performed, concurrent radiographic investigations can be helpful.

Endoscopy_UCTN_Code_CCL_1AD_2AJ
B. Bigler ${ }^{1}$, T. Steffen ${ }^{2}$, J. Binek ${ }^{1}$

1 Division of Gastroenterology and Hepatology, Department of Internal Medicine, Kantonsspital, St Gallen, Switzerland

2 Department of Surgery, Kantonsspital, St Gallen, Switzerland

\section{References}

1 Banac S, Ahel V, Rozmanic V et al. Congenital diaphragmatic hernia in older children. Acta Med Croatica 2004; 58: 225 - 228

2 Weber TR, Tracy TJr, Bailey PV et al. Congenital diaphragmatic hernia beyond infancy. Am J Surg 1991; 162: 643-646

3 Kitano Y, Lally KP, Lally PA. Congenital Diaphragmatic Hernia Study Group. Late-presenting congenital diaphragmatic hernia. J Pediatr Surg 2005; 40: 1839- 1843

4 Baglai M, Dorobisz U. Late-presenting congenital diaphragmatic hernia in children: a literature review. Pediatr Radiol 2005; 35 : $478-488$

5 Sener RN, Tugran C, Yorulmaz I et al. Bilateral large Bochdalek hernias in an adult. Clin Imaging 1995; 19: 40-42

\section{Bibliography}

DOI $10.1055 / s-2007-995494$

Endoscopy 2008; 40: E76

(c) Georg Thieme Verlag KG Stuttgart · New York . ISSN 0013-726X

\section{Corresponding author}

\section{J. Binek, MD}

Division of Gastroenterology and Hepatology Department of Internal Medicine Kantonsspital 9007 St Gallen

Switzerland

Fax: + 41-71-4942862

janek.binek@kssg.ch 